OPEN ACCESS

Edited by:

Graham Moore,

Cardiff University, United Kingdom

Reviewed by:

Emanuele Castagno,

Ospedale Pediatrico Regina

Margherita, Italy

Immacolata Dall'Oglio,

Bambino Gesù Children's Hospital

(IRCCS), Italy

*Correspondence:

Anne Geweniger

anne.geweniger@uniklinik-freiburg.de

Specialty section:

This article was submitted to

Children and Health,

a section of the journa

Frontiers in Pediatrics

Received: 15 August 2021 Accepted: 18 January 2022

Published: 10 February 2022

Citation:

Geweniger A, Barth M, Haddad AD, Högl H, Insan S, Mund A and

Langer $T$ (2022) Impact of the

COVID-19 Pandemic on Mental Health Outcomes of Healthy Children,

Children With Special Health Care

Needs and Their Caregivers-Results of a Cross-Sectional Study.

Front. Pediatr. 10:759066.

doi: 10.3389/fped.2022.759066

\section{Impact of the COVID-19 Pandemic on Mental Health Outcomes of Healthy Children, Children With Special Health Care Needs and Their Caregivers-Results of a Cross-Sectional Study}

\author{
Anne Geweniger ${ }^{1 *}$, Michael Barth ${ }^{2}$, Anneke D. Haddad ${ }^{2}$, Henriette Högl $^{3}$, Shrabon Insan ${ }^{1}$, \\ Annette Mund $^{3}$ and Thorsten Langer ${ }^{1}$ \\ ${ }^{1}$ Center for Pediatrics, Department of Neuropediatrics and Muscle Disorders, Medical Center - University of Freiburg, \\ Freiburg, Germany, ${ }^{2}$ Center for Pediatrics, Department of General Pediatrics, Adolescent Medicine and Neonatology, \\ Medical Center - University of Freiburg, Freiburg, Germany, ${ }^{3}$ Kindernetzwerk e.V., Mainaschaff, Germany
}

Background: Several studies have described widening inequalities as a result of the COVID-19 pandemic, mostly for adult populations. Children and adolescents are particularly impacted by the indirect effects of the pandemic and lockdown measures, such as reduced access to or delays in health care and school closures. National surveys in several countries also show a rising mental health burden in children and adolescents during the COVID-19 pandemic. Children with special health care needs are a particularly vulnerable group in this context as they rely on a wide range of services, which were mostly suspended during the first wave of the pandemic. This study aims: (1) to describe the mental health outcomes of children with and without special healthcare needs and of their caregivers following the first national lockdown in Germany; (2) to investigate variations in mental health outcomes and measures of pandemic burden according to socioeconomic status; (3) to assess the impact of socioeconomic status, disease complexity and psychosocial burden on parent-reported child mental health problems.

Methods: We conducted an online survey among 1,619 caregivers of children aged 1-18 years from August 11th until October 5th 2020. Participants were recruited both from families of children with special healthcare needs and of healthy children. Inequalities were analysed by descriptive statistics, simple and hierarchical logistic regression modelling to explore the association between socioeconomic status and psychological outcome measures, disease complexity and general burden related to COVID-19.

Results: There was a high prevalence of $57.4 \%$ of parent-reported mental health problems in children and of a positive screening score for depression in 30.9\% of parents. Parent-reported mental health problems were more likely to affect children with low socioeconomic status, with complex chronic disease and those whose parents screened positive for depression. 
Conclusions: This study highlights inequalities in parent-reported child mental health outcomes by socioeconomic status and disease complexity in a large sample of German families with and without children with special health care needs. Political measures should put children at the centre and aim to mitigate the unequal impact of the COVID-19 pandemic, particularly on the mental health of vulnerable children.

Keywords: inequalities, socioeconomic status, mental health, COVID-19, children with special healthcare needs, caregivers, pandemic

\section{INTRODUCTION}

There is growing concern that COVID-19 widens and exposes pre-existing inequalities (1). Adults of ethnic and minority background, of low socioeconomic status (SES) or those living in deprived neighbourhoods suffer from higher COVID-related morbidity and mortality $(2,3)$. While inequalities have been described for the adult population, research into pandemicrelated inequalities affecting children and adolescents is rare. Measures to control the pandemic, mostly lockdown- and social distancing measures, have lead to a disruption of societal functioning in many countries worldwide. As SARS-CoV2 infection in children leads mostly to mild disease, it is particularly the indirect impact of the pandemic that affects children and adolescents (4-7). These indirect effects are wide-ranging and include reduced access to or delays in health care and immunisation services; educational deficits as a result of school closures; food insecurity; increased risk of child abuse and violence against children; poor mental health and adverse child development outcomes $(4,5,8-10)$.

Children and adolescents have been identified as a particularly vulnerable group in this current pandemic, especially with regards to their mental health (11). National surveys in several countries show a rising mental health burden in children and adolescents as a consequence of the COVID-19 pandemic. In Canada, 25\% of parents reported worsened child mental health outcomes (12). In the US, an increase in emergency department visits for mental health problems was observed locally and parents reported an increase in child behavioural problems in a national survey $(8,13)$. In the UK, the proportion of mental health problems increased from $10.8 \%$ in 2017 to $16.0 \%$ in 2020 in children aged 5-16 years (14). Meanwhile, some studies suggest that there is decreased access to mental health services both due to lower referrals and reduced help-seeking out of fear of contracting SARS-CoV2 (14-16).

In Germany, the first official case of COVID-19 was registered on January $27^{\text {th }} 2020$. Depending on the respective federal state, schools closed from about the middle of March until May $4^{\text {th }}$ 2020 and a first national lockdown was in place from March $22^{\text {nd }}$ until May $4^{\text {th }}$ 2020. A national representative study, conducted between May $26^{\text {th }}$ and June $10^{\text {th }}$ following the first lockdown found an increase of mental health problems in children and adolescents from $9.9 \%$ in 2017 to $17.8 \%$ in 2020 and an increase in anxiety from 14.9 to $24.1 \%$ (17).

With the daily life of families and children being disrupted by school closures, social distancing and economic consequences of lockdown measures, resulting parental stress and increase in family conflict is likely to have an additional impact on child mental health $(7,11,12,18-21)$. For instance, during the first wave of COVID-19 in 2020 in the UK, children with parents experiencing psychological distress were three times more likely to have mental health problems (14). In Spain, an increase in mental health problems of adolescents was associated with worsened family relationships and stress in the family (21).

The association between low SES and child mental health outcomes has been widely described $(12,17,22-24)$. In the current pandemic, children from households in the UK that had fallen behind with payments were more than twice as likely to have mental health problems $(14,15)$. A study from China reports that both low parental education and income were associated with child mental health problems (25). In Germany, children from a low socioeconomic background were significantly more affected by an increase in mental health problems and anxiety following the first lockdown (17).

Children with special health care needs are a vulnerable population dependent on services relating to health, education and protection which were mostly suspended during the first wave of the pandemic (7). Their caregivers already face a higher mental health burden as well as higher rates of work loss and financial strain due to COVID-19 (26-29). These families and children are particularly affected by disintegration of support networks, as most services required cannot be delivered outside of specialist settings and it is difficult for parents or caregivers to replace the wider support those children usually receive $(6,30)$. As a consequence, studies suggest that children with special health care needs are facing an increase in mental health problems, delayed access to health care and risk falling even more behind in their education $(6,27,28,30-32)$.

Despite emerging evidence, so far few research has specifically focussed on the impact of inequalities and social determinants on child health in general, and on vulnerable children in particular, during the COVID-19 pandemic (5).

Following calls for "research that unpicks the mechanisms of differential exposure, vulnerability and consequences, identifying the most effective policy entry points" (2), our study aims to investigate the impact of lockdown measures during the first wave of the COVID-19 pandemic in Germany, and of socioeconomic inequalities on the mental health burden of children with and without special health care needs, and of their caregivers. This study aims: 
(1) to describe the mental health outcomes of children with and without special healthcare needs and of their caregivers following the first national lockdown in Germany.

(2) to investigate variations in mental health outcomes and measures of pandemic burden according to socioeconomic status.

(3) to assess the impact of socioeconomic status, disease complexity and psychosocial burden on parent-reported child mental health problems.

\section{METHODS}

\section{Study Design}

This study represents the first of three rounds of data collection of a sequential cross-sectional study with a survey period of 1.5 years. To this end, an online survey administered through the REDcap $\odot$ system was conducted from August 11th until October 5th 2020 among caregivers of children aged 1-18 years.

Participants were recruited by convenience and nonprobabilistic snowball sampling through the Kindernetzwerk e.V., a patient organisation for families of children with chronic diseases and disabilities, which unites a network of 236 patient organisations with about 200,000 members; through promoting the link on free access websites; and via social und public media. Both families with children with chronic diseases or disabilities, and families with healthy children as comparison group were encouraged to participate in the survey.

The study is registered with the German Registry for Clinical Studies (DRKS00022868) and was approved by the local ethics committee of Freiburg University (Approval number 377/20).

\section{Measures}

\section{Socioeconomic Status (SES)}

Following the approach of the National Health Interview and Examination Survey for Children and Adolescents (KiGGS) in Germany (33), an index measuring SES was constructed as the sum of three indicators: household net equivalent income, parental education and parental occupation. Household net equivalent income was calculated as the monthly net family income adjusted for household size using a modified scale proposed by the Organisation for Economic Cooperation and Development [OECD, (33)]. Weights were assigned to the household head $(=1)$, any additional adult $(=0.5)$ and children $(=0.3)$. The monthly net family income was divided by the sum of weights per household. For parental education and occupation, the respective higher level of each parent was assigned to each household. The SES index was first divided into quintiles and then grouped into three levels: low (quintile 1), middle (quintiles 2-4) and high (quintile 5) SES, allowing for comparison between the most disadvantaged $20 \%$ and the most advantaged $20 \%$ of families in the sample.

\section{Strengths and Difficulties Questionnaire (SDQ)}

The SDQ is an established and validated screening instrument for mental health problems in children and adolescents. The standard parent-reported version of the SDQ applies to children aged 4-16 years (34). The German version of the parent-reported scale has equal validity and reliability compared to the original English version (35-37). Four subscales (hyperactivity/inattention, emotional symptoms, conduct problems, peer problems) are covered by the Total Difficulties Score, which has values from $0-40$; higher scores indicate more serious mental health problems. The preschool version of the SDQ differs from the standard parent-reported SDQ in three items, which are adjusted to account for an age-appropriate context (www.sdqinfo.org) (38). The German preschool version has been validated in a sample of 3-5 year old children (39). In line with these previous studies, we used age-appropriate versions of the SDQ for parents of children aged older than 2 years. Following published standards, we used a cut-off of 13 or higher to group slightly raised and high scores as compared to average scores of $0-12(37,40)$. The SDQ relates to child or adolescent behaviour during the previous 6 months and has been used as part of the National Health Interview and Examination Survey for Children and Adolescents (KiGGS) (40).

\section{WHO-5 Wellbeing Index (WHO-5)}

The WHO-5 is a widely used brief screening questionnaire to assess mental health wellbeing. Its validity and reliability has been documented in various studies and it can be used as a screening tool for depression (41). Referring to the previous 2 weeks, the WHO-5 assesses wellbeing in five questions and a six point Likert-Scale, resulting in a raw score of $0-25$. The raw score is multiplied by four to give the final score of $0-100$, with 100 representing the best imaginable wellbeing. The cut-off point for depression screening is 50 (41).

\section{Children With Special Health Care Needs (CSHCN-Screener)}

The CSHCN Screener is a brief standardised survey which aims at identifying children with chronic physical, mental, behavioural or other conditions who require health and related services beyond the average needs of their peers (42). Five parent-reported items assess (1) the need or use of prescription medication; (2) above-routine use of medical, mental health or educational services compared to other children of the same age; (3) activity limitations in day-to-day life compared to similar age children; (4) need or use of specialised therapies; and (5) need or use of treatment or counselling for an emotional, behavioural or developmental condition. A maximum score of 5 can be obtained, with higher scores indicating higher complexity of health care needs and more severe conditions (43). Several ways of stratifying children according to their CSHCN score have been described $(43,44)$. We categorised children into three groups: healthy (CSHCN score $=0$ ), chronic conditions (CSHCN score $\leq 2$ ) and complex chronic conditions (CSHCN score $\geq 3$ ). The CSHCN Screener has been used as part of the National Health Interview and Examination Survey for Children and Adolescents (KiGGS) in Germany (45).

\section{COVID-19 and Lockdown-Related Burden}

We designed several items assessing the general burden of the impact of the pandemic on families and children, covering financial difficulties, home schooling and child development, 
social support and a general feeling of being burdened by the pandemic restrictions.

\section{Sociodemographic Measures}

Sociodemographic measures relating to parents included respondent's age and gender, relationship status and relation to the child, education, occupation, monthly net family income and household size as well as area of residence and country of birth. Measures relating to the child included age and gender.

\section{Statistical Methods}

Descriptive statistics comprised frequencies, means and standard deviations for all variables. Inequalities in the impact of the first wave of the COVID-19 pandemic in Germany were analysed by simple logistic regression to obtain unadjusted Odds Ratios for the association between SES and psychological outcome measures, disease complexity and general burden related to COVID-19 respectively.

Theory-driven hierarchical (blockwise) logistic regression modelling was performed to estimate adjusted Odds Ratios for the association of child mental health problems with SES, disease complexity, parental mental health and pandemic burden. Block 1 represents associations between child mental health problems, gender, disease complexity and SES, which have been widely described. Block 2 represents potential associations between parental wellbeing during the pandemic and child mental health problems. Block 3 represents additional COVID19 related burden for both parents and children. A general model (model 1) was compared with three models stratifying for disease complexity to control for confounding (models 24). The analysis was restricted to children older than 2 years of age, in accordance with the SDQ age limit as outlined above:

\section{Model 1:}

- block 1: child's age, gender, socioeconomic status, disease complexity

- block 2: WHO-5

- block 3: increase in family conflict, financial difficulties, inadequate educational support, negative effect of school closures on child's development, inadequate social support, area of residence

Model 2: Model 1 restricted to healthy children.

Model 3: Model 1 restricted to children with chronic conditions.

Model 4: Model 1 restricted to children with complex chronic conditions.

The overall model fit was assessed by $\mathrm{R}^{2}$ statistics. Model sensitivity and $\mathrm{R}^{2}$ statistics are reported for each model. Adjusted Odds Ratios are reported with the corresponding 95\% confidence intervals (95\% CI). Prior to logistic regression modelling, we replaced missing data of outcome and exposure variables using multiple linear imputation to include all cases $(N=1,619)$. Therefore, we proved the missing at random assumption by including all variables of the logistic regression model and COVID-19 and lockdown-related burden variables. Missing values ranged from 15-24\% for all variables.

Analysis was conducted using IBM SPSS Version 27.0.

\section{RESULTS}

\section{Sociodemographic Characteristics}

Of 2004 persons who accessed the survey, 1,619 had children aged 18 years or younger, thus meeting the inclusion criteria.

The mean age of respondents was 41 years (SD 6.94) and $90.1 \%(n=1,458)$ were female. The mean age of children was 8 years (SD 4.19$)$ and $55.5 \%(n=899)$ were male. The majority lived with their biological parents in the same household (Table 1). In $84.3 \%(n=1,071)$ of cases both parents were born in Germany. Most parents had a high educational level and worked in full-time or free-lance jobs $(n=1,173$ [72.5\%] and $n=1,214$ [75.0\%] respectively). Among children, 29.5\% $(n=478)$ fulfilled the criteria for complex chronic disease according to the CSHCN Screener, $11.9 \%(n=193)$ for chronic disease and the majority $(58.6 \%, n=948)$ was healthy.

Among all 671 children with special health care needs, 69.4\% $(n=466)$ had a physical impairment, $73.0 \%(n=$ 490) had a behavioural or sensory impairment, and 53.7\% ( $n$ $=360$ ) had impaired speech or understanding. Difficulties in communication were reported for $27.8 \%(n=188)$ children, $1.6 \%$ $(n=11)$ depended on home ventilation and $5.6 \%(n=38)$ had a feeding tube.

\section{Mental Health and Perceived Burden of the Pandemic}

For parents, the mean WHO-5 score was 62.8 (SD 20.8), with $30.9 \%$ ( $n=501$ ) having a score below the screening cut-off for depression. For children, the parent-reported mean SDQscore was 13.5 (SD 5.2), with 57.4\% $(n=930)$ of children having a score at or above the cut-off level of 13, indicating slightly raised or high scores. There was very strong evidence for an association of the SDQ score and disease complexity $\left(\chi^{2}(\mathrm{df}=2)=104.06 ; p<0.001\right)$. Among healthy children, $52.8 \%(n=501)$ had average SDQ scores, whereas a majority of children with chronic and complex chronic disease had slightly raised or high SDQ-scores $(n=126$ [65.3\%] and $n=$ 357 [74.7\%] respectively). Most parents felt burdened by the pandemic restrictions $(n=1,445[89 \%])$ and saw their children burdened as well ( $n=1,426[88.1 \%])$. About half the parents felt burdened by home schooling, perceived the educational support as inadequate and saw a negative effect of school closures on their child's development (Table 2). More than one third of parents reported an increase in family conflict and felt that social support by friends or relatives was inadequate $(n=623$ [38.5\%] and $n=563$ [34.8\%] respectively).

\section{Socioeconomic Inequalities}

Stratifying the sample according to the SES index showed that $18.6 \%(n=301)$ of all families had a low SES, $51.8 \%(n=839)$ were in the middle group, whereas $29.6 \%(n=479)$ had a high SES. There were marked differences between families of low and 
TABLE 1 | Sociodemographic characteristics ( $N=1619)$.

\begin{tabular}{lcc}
\hline & Mean (SD) & Range \\
\hline Age in years & & \\
$\quad$ Responding parent & $41.2(6.94)$ & \\
$\quad$ All children & $8.14(4.19)$ & $1-19$ \\
$\quad$ Children with SHCN & $8.99(4.27)$ & $0-18$ \\
Number of children per household & $1.95(0.83)$ & $1-7$ \\
Household size & $3.98(0.99)$ & $1-9$ \\
\hline & $\boldsymbol{n}$ & $\%$
\end{tabular}

Gender of respondent

Male
Female
Gender of child
Male
Female
Diverse
Relation to child ( $N=1,307$ )
Biological mother
Biological father
Other
Relationship status
With partner, in same hous

With partner, in same household

With partner, not in same household

No partner

Country of birth of parents $(N=1,271)$

Both in Germany

One parent in Germany, one elsewhere

Both elsewhere

Place of residence

City (>100,000 inhabitants)

Surroundings of a city with $>100,000$ inhabitants

Town (20,000- 100000 inhabitants)

Small town (5,000 - 20,000 inhabitants)

Rural municipality ( $<5,000$ inhabitants)

Disease complexity of child

Healthy (CSHCN = 0)

Chronic disease (CSHCN $\leq 2$ criteria)

Complex chronic disease (CSHCN $\geq 3$ criteria)

Educational level

No qualification

Certificate of Secondary Education (9 years of

schooling)

General Certificate of Secondary Education

(10 years of schooling)

A-levels (qualification at age 18)

Employment status

Inactive or unemployed

Maternity leave or parental leave

Short term or temporary employment

Part-time

Full-time or free lance

\section{1}

1,458

899

710

10

1,136

125

46

1,441

46

132

1,071

154

46

558

226

238

235

362

948

193

478

1

36

409

1,173

30

23

98

254

1,214

Household net equivalent income (monthly, in Euro, quintiles)

Up to 850
368
TABLE 1 | Continued

\begin{tabular}{lll}
\hline & $\boldsymbol{n}$ & $\%$ \\
\hline $850-1000$ & 312 & 19.3 \\
$1000-1300$ & 314 & 19.4 \\
$1300-1400$ & 364 & 22.5 \\
More than 1,400 (maximum: 2,750 €) & 261 & 16.1 \\
\hline
\end{tabular}

SD, Standard deviation; percentages reported as row percentages.

TABLE 2 | Negative effects of the first lockdown on families; $N=1,619$.

\begin{tabular}{lcc}
\hline & $\boldsymbol{n}$ & $\%$ \\
\hline Increase in family conflict & 623 & 38.5 \\
Inadequate social support & 563 & 34.8 \\
Financial difficulties due to the pandemic & 268 & 16.6 \\
Feeling burdened by home schooling & 937 & 57.9 \\
Inadequate educational support & 857 & 52.9 \\
Negative effect of school closures on child's development & 807 & 49.8 \\
Feeling burdened by pandemic restrictions & & \\
$\quad$ Respondent & 1,445 & 89.3 \\
$\quad$ Child or children & 1,426 & 88.1 \\
$\quad$ Child with chronic condition $(N=515)$ & 418 & 81.2 \\
\hline
\end{tabular}

high SES. There was strong evidence for an unequal distribution of disease complexity among children in different socioeconomic groups, with more children with complex chronic conditions living in families of low socioeconomic status $\left(\mathrm{X}^{2}(\mathrm{df}=4)=49.04\right.$; $p<0.001$; Figure 1 and Supplementary Table S1). Looking at mental health outcomes, parents of low SES had $86 \%$ higher odds of a score suggestive of depression in the WHO-5 screening than parents with a high SES (crude OR 1.86 [1.37; 2.54]; $p<0.001$; Table 3). Similarly, children living in families with a low SES had twice the odds of parent-reported mental health problems compared to children in the highest SES group (crude OR 2.32 $[1.71 ; 3.14] ; p<0.001)$. Families with a low socioeconomic status had seven times the odds of financial difficulties compared to families in the highest group and had $90 \%$ higher odds of reporting inadequate social support (crude OR 7.03 [4.59; 10.77]; $p<0.001$ and crude OR 1.90 [1.41; 2.57]; $p<0.001$ ). There was weak evidence for a difference in the burden of homeschooling and increase of family conflict between the respective SES groups (Table 3). No differences were observed for educational support and the negative effect of school closures on the child's development.

\section{Impact of Socioeconomic Status and Psychosocial Burden on Child Mental Health}

The results from hierarchical logistic regression modelling are displayed in Table 4 for the baseline model and in the Supplementary Table S2 for models 2-4.

The baseline model 1 included all children older than 2 years (34). The variance explained by model 1 after the first block 


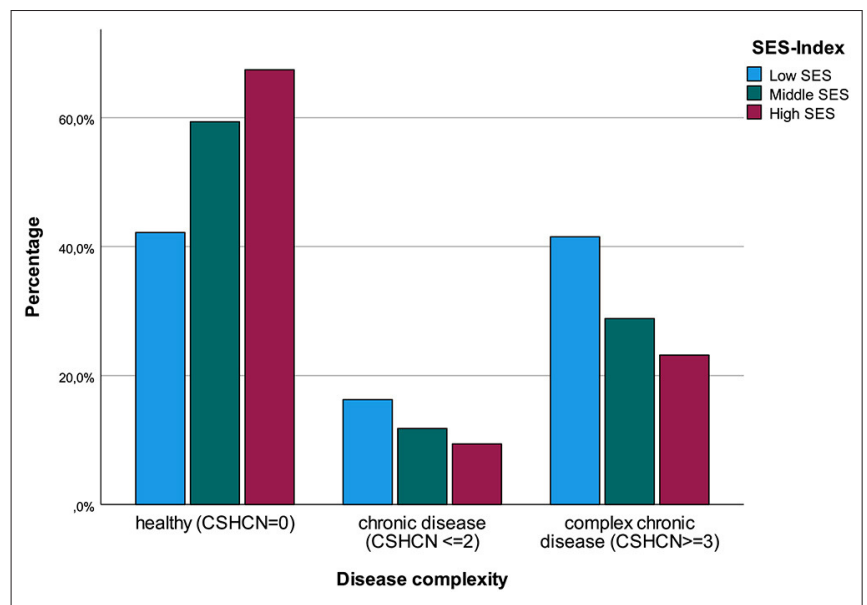

FIGURE 1 | Stratified analysis of disease complexity by socioeconomic status ( $N=1619)$. SES, socioeconomic status; CSHCN, Children with Special Health Care Needs Screener.

TABLE 3 | Stratified analysis of psychosocial outcomes and perceived burden by socioeconomic status $(N=1619)$.

\begin{tabular}{|c|c|c|c|}
\hline & $\begin{array}{c}\text { Low SES } \\
\text { OR }(95 \% \mathrm{Cl})\end{array}$ & OR $(95 \% \mathrm{Cl})$ & $\begin{array}{c}p \text {-value } \\
\text { (reference group: } \\
\text { High SES) }\end{array}$ \\
\hline $\mathrm{WHO}-5 \leq 50$ & $\begin{array}{c}1.86 \\
(1.37 ; 2.54)\end{array}$ & $\begin{array}{c}1.33 \\
(1.03 ; 1.71)\end{array}$ & $<0.001$ \\
\hline SDQ total score $\geq 13$ & $\begin{array}{c}2.32 \\
(1.71 ; 3.14)\end{array}$ & $\begin{array}{c}1.39 \\
(1.11 ; 1.74)\end{array}$ & $<0.001$ \\
\hline Increase in family conflict & $\begin{array}{c}1.41 \\
(1.05 ; 1.89)\end{array}$ & $\begin{array}{c}1.17 \\
(0.93 ; 1.48)\end{array}$ & 0.075 \\
\hline Inadequate social support & $\begin{array}{c}1.90 \\
(1.41 ; 2.57)\end{array}$ & $\begin{array}{c}1.23 \\
(0.97 ; 1.57)\end{array}$ & $<0.001$ \\
\hline Financial difficulties & $\begin{array}{c}7.03 \\
(4.59 ; 10.77)\end{array}$ & $\begin{array}{c}2.52 \\
(1.69 ; 3.76)\end{array}$ & $<0.001$ \\
\hline $\begin{array}{l}\text { Inadequate educational } \\
\text { support }\end{array}$ & $\begin{array}{c}1.14 \\
(0.85 ; 1.52)\end{array}$ & $\begin{array}{c}1.06 \\
(0.85 ; 1.33)\end{array}$ & 0.673 \\
\hline $\begin{array}{l}\text { Feeling burdened by home } \\
\text { schooling }\end{array}$ & $\begin{array}{c}1.26 \\
(0.94 ; 1.69)\end{array}$ & $\begin{array}{c}1.30 \\
(1.04 ; 1.64)\end{array}$ & 0.063 \\
\hline $\begin{array}{l}\text { Negative effect of school } \\
\text { closures on child's } \\
\text { development }\end{array}$ & $\begin{array}{c}1.05 \\
(0.78 ; 1.40)\end{array}$ & $\begin{array}{c}1.19 \\
(0.95 ; 1.49)\end{array}$ & 0.278 \\
\hline
\end{tabular}

Unadjusted Odds Ratios (OR) are estimated by logistic regression modelling. SES, socioeconomic status; CSHCN, Children with Special Health Care Needs Screener; WHO-5, WHO-5 Wellbeing Index, SDQ, Strengths and Difficulties Questionnaire.

including disease complexity, SES index, age and gender of the child was $\mathrm{R}^{2}=0.13$. The biggest increase in explained variance was after block 3, which included psychosocial explanatory variables $\left(\mathrm{R}^{2}=0.28\right.$ and $\left.\Delta \mathrm{R}^{2}=0.09\right)$. After completion of block 3 , the baseline model 1 suggests very strong evidence for an association of the child's disease complexity, low socioeconomic status, parental mental health and psychosocial burden of the COVID-19 pandemic with parent-reported child mental health problems. After controlling for confounding effects of age, gender and socioeconomic status, children with complex chronic
TABLE 4 | Impact of socioeconomic status and psychosocial burden on parent-reported child mental health problems.

\begin{tabular}{|c|c|c|c|}
\hline \multirow{2}{*}{$\begin{array}{l}\text { Variables } \\
\text { Block } 1\end{array}$} & \multicolumn{3}{|c|}{$\begin{array}{c}\text { Model } 1 \\
\text { All children } \\
(N=1,479)\end{array}$} \\
\hline & OR & $95 \% \mathrm{Cl}$ & $p$ \\
\hline \multicolumn{4}{|l|}{ Disease complexity } \\
\hline \multicolumn{4}{|l|}{ Healthy (referent) } \\
\hline Chronic condition & 2.34 & $1.62 ; 3.37$ & $<0.001$ \\
\hline Complex chronic condition & 3.07 & $2.33 ; 4.04$ & $<0.001$ \\
\hline \multicolumn{4}{|l|}{ SES-Index } \\
\hline Low & 1.65 & $1.14 ; 2.38$ & 0.007 \\
\hline Middle & 1.27 & $0.97 ; 1.66$ & 0.084 \\
\hline \multicolumn{4}{|l|}{ High (referent) } \\
\hline Age of child & 0.96 & $0.93 ; 0.99$ & 0.004 \\
\hline \multicolumn{4}{|l|}{ Gender of child } \\
\hline \multicolumn{4}{|l|}{ Male (referent) } \\
\hline Female & 0.82 & $0.65 ; 1.04$ & 0.095 \\
\hline Diverse & 2.55 & $0.46 ; 14.06$ & 0.283 \\
\hline \multicolumn{4}{|l|}{ Model fit after block 1} \\
\hline Nagelkerke's $\mathrm{R}^{2}$ & 0.13 & & \\
\hline Block 2 & OR & $95 \% \mathrm{CI}$ & $p$ \\
\hline WHO-5 Score $\leq 50$ & 1.91 & $1.47 ; 2.49$ & $<0.001$ \\
\hline \multicolumn{4}{|l|}{ Model fit after block 2} \\
\hline Nagelkerke's R² & 0.19 & & \\
\hline$\Delta \mathrm{R}^{2}$ & 0.05 & & \\
\hline Block 3 & OR & $95 \% \mathrm{Cl}$ & $p$ \\
\hline Increase in family conflict & 2.05 & $1.59 ; 2.62$ & $<0.001$ \\
\hline Financial difficulties & 1.60 & $1.15 ; 2.23$ & 0.006 \\
\hline Inadequate educational support & 1.72 & $1.33 ; 2.22$ & $<0.001$ \\
\hline $\begin{array}{l}\text { Negative effect of school closures on } \\
\text { child's development }\end{array}$ & 1.39 & $1.09 ; 1.78$ & 0.008 \\
\hline Inadequate social support & 1.39 & $1.07 ; 1.80$ & 0.013 \\
\hline \multicolumn{4}{|l|}{ Area of residence } \\
\hline \multicolumn{4}{|l|}{ City (referent) } \\
\hline Surroundings of a city & 1.21 & $0.84 ; 1.74$ & 0.315 \\
\hline Town & 1.67 & $1.16 ; 2.42$ & 0.006 \\
\hline Small town & 1.46 & $1.02 ; 2.10$ & 0.039 \\
\hline Rural municipality & 1.32 & $0.96 ; 1.82$ & 0.087 \\
\hline \multicolumn{4}{|l|}{ Model fit after block 3} \\
\hline Nagelkerke's $\mathrm{R}^{2}$ & & 0.28 & \\
\hline$\Delta R^{2}$ & & 0.09 & \\
\hline $\begin{array}{l}\% \text { correct prediction of SDQ Score } \\
\geq 13\end{array}$ & & 75.0 & \\
\hline
\end{tabular}

Hierarchical logistic regression modelling of the outcome SDQ total score $\geq 13$ in children older than 2 years of age. Adjusted Odds Ratios with $p<0.05$ in bold.

$S D Q$, Strengths and Difficulties Questionnaire; CSHCN, Children with Special Health Care Needs Screener; SES-Index, Index of socioeconomic status.

diseases had 3 times the odds of parent-reported mental health problems (i.e., SDQ total score $\geq 13$ ) compared with healthy 
children in the baseline group (adjusted OR 3.07 [2.33; 4.04]; $p$ $<0.001$ ). Children of low socioeconomic status or from families with financial difficulties had $60 \%$ higher odds of parent-reported mental health problems compared to children from a high socioeconomic background (adjusted OR 1.65 [1.14; 2.38] and $1.60[1.15 ; 2.23]$ respectively). Children whose parents screened positive for depression in the WHO-5 or reported an increase in family conflict due to the pandemic had twice the odds of parent reported mental health problems compared to the baseline group (adjusted OR 1.91 [1.47; 2.49] and 2.05 [1.59;2.62]; $p<$ 0.001 respectively). Area of residence in a town or small town was associated with higher odds of parent-reported mental health problems (adjusted OR 1.67 [1.16; 2.42] and $1.46[1.02 ; 2.10]$ ). Conversely, older children had lower odds of a total SDQ-score $\geq 13$ (adjusted OR 0.96 [0.93; 0.99]; $p=0.004$ ).

Model 2 for healthy children explained less variance after block $1\left(R^{2}=0.05\right)$ than model 1 . Similarly, the biggest difference in explained variance was between block 2 and $3\left(\mathrm{R}^{2}=0.22\right.$ and $\Delta \mathrm{R}^{2}=0.12$ ), however the overall variance explained was lower than for model 1 . Model 2 still shows very strong evidence for an association of parental mental health, increase in family conflict, consequences of school closures and strong evidence for an association of low SES with parent-reported child mental health problems. Financial difficulties too were still associated with parent-reported child mental health problems, but not as strongly as in model 1 (adjusted OR 1.58 [1.02; 2.45], $p=0.40$ ).

The variance explained by model 3 including children with less complex chronic disease after block 1 was $\mathrm{R}^{2}=0.10$. Overall, the explained variance increased only to $\mathrm{R}^{2}=0.19$ after block 3 , with $\Delta \mathrm{R}^{2}=0.04$ after block 2 and $\Delta \mathrm{R}^{2}=0.06$ after block 3. The model suggests strong evidence for an inverse association of age and parent-reported mental health problems 1 (adjusted OR 0.88 [0.80; 0.98], $p=0.014)$. Apart from weak evidence of an association with parental mental wellbeing (adjusted OR $2.10[0.98 ; 4.48] ; p=0.056)$, none of the other exposure variables included in the model show a significant association with the outcome.

Following block 1, the variance explained by model 4 for children with complex chronic diseases was the lowest of all four models at $\mathrm{R}^{2}=0.03$. However, it also had the largest increases in explained variance after blocks 2 and 3 of all four models $(\Delta$ $\mathrm{R}^{2}=0.08$ after block 2 and $\Delta \mathrm{R}^{2}=0.12$ after block 3 ). Overall, the variance explained after block 3 was $\mathrm{R}^{2}=0.23$. Looking at mental health outcomes in children with complex chronic diseases, model 4 shows a higher influence of psychosocial variables on child mental health than the other models. Here, parents who screen positive for depression had 2.3 times the odds of reporting child mental health problems (adjusted OR 2.35 [1.36; 4.05], $p=0.002)$. Similarly, children whose parents report an increase in family conflict have 2.4 times the odds of parentreported mental health problems compared to the baseline group (Table 4). Some weak evidence suggestive of an association of low SES with mental health problems remains (adjusted OR 1.99 [0.93; 4.01], $p=0.056)$. However, in this model stratified according to disease complexity, financial difficulties and age show no association with parent-reported child mental health problems anymore.

\section{DISCUSSION}

This is to our knowledge the first study reporting inequalities in mental health outcomes in a large sample of children with and without special health care needs and their parents in Germany. We found a high prevalence of $57.4 \%$ of parent-reported mental health problems in children and a positive screening score for depression in $30.9 \%$ of parents. Parent-reported mental health problems were more likely to affect children from low SES, with complex chronic disease and those whose parents screened positive for depression.

\section{Child and Parental Mental Health}

Our results suggest a high mental health burden during the pandemic in both children and their families, particularly mothers. The prevalence of parent-reported child mental health problems in our sample was $57.4 \%$. This is a markedly higher prevalence than the prevalence of $30.4 \%$ after the first lockdown in the representative German study by Ravens-Sieberer et al. using the same SDQ cut off values as our study (23). However, our study is not based on a representative sample and the high proportion of children with chronic disease might lead to a higher prevalence of child mental health problems in our sample than in the general population.

The mean WHO-5 Score as indicator of wellbeing in our study was 62.8 , which is slightly lower than the referent mean score of 65.7 reported for German adults in the European Quality of Life survey [(41), supplement]. $30.9 \%$ of parents had a WHO5 score below the cut off for depression. The European Health Interview Survey 2014/2015 reports for Germany a prevalence of depression of $9.2 \%$ in the general population and $10.8 \%$ for women (46). Though not resulting from a representative sample, our data suggests both lower parental wellbeing and a higher prevalence of depression compared to the general population. The higher mental health impact of the pandemic on parents has also been described in a representative study from Canada, where $44.3 \%$ of parents reported deteriorated mental health compared to $35.6 \%$ of adults without children $<18$ years at home (12).

Our data suggests that children whose parents screened positive for depression in the WHO-5 had twice the odds of parent-reported mental health problems compared to the baseline group. The association of parental and child mental health has been widely acknowledged $(9,47)$. During the current pandemic, $10 \%$ of US families reported both worsening of their own and their child's mental health (8). An Italian survey described the reciprocal relationship of parental psychological distress and child emotional and behavioural problems, especially for single parents or parents of younger children (48). The authors highlight the risk of a vicious circle where parental psychological distress is maintained by children's emotional and behavioural difficulties and aggravates those difficulties in turn.

Similarly, an increase in family conflict was associated with higher odds of parent-reported child mental health problems. This echoes findings from a representative UK study conducted during the first wave of the COVID-19 pandemic. They found that $28.3 \%$ of children with mental health problems lived in 
a family which reported problems with family functioning, compared to $11.7 \%$ of children without mental health problems (14). The same study also reported that children with parentreported mental health problems were less likely to have regular support from their school or college (14). Our findings support this association, as both insufficient social and educational support were associated with parent-reported child mental health problems.

\section{Socioeconomic Inequalities and Mental Health}

We found that children of low socioeconomic status and children from families with financial difficulties had $60 \%$ higher odds of parent-reported mental health problems, compared with children from a high socioeconomic background or from families without financial difficulties. Children from lower socioeconomic background have repeatedly been found to be more likely to have mental health problems $(22,24)$. This inequality persists in the current pandemic and our results seem to be in line with a rise in child and adolescent mental health problems in Germany, which was found to disproportionately affect children whose parents had a lower educational or migration background (17, 23). Similarly, a study conducted in a sample of hourly service workers with young children in the US reports an association of income or job loss, parental and child psychological wellbeing. The number of pandemic-related hardships was related to all psychological well-being measures (20).

The association between low SES and parent-reported child mental health problems remained strong after stratifying the sample according to disease complexity to account for potential confounding. Following stratification, children without complex chronic disease from a low SES had $73 \%$ higher odds of parent-reported mental health problems compared with children from a high socioeconomic background. In addition, there was suggestive evidence that children with complex chronic disease from a low SES have even twice the odds of parent-reported mental health problems compared to children from a higher SES. Low SES has been acknowledged to likely be both a cause and a consequence of childhood disability, though its position on the causal pathway remains uncertain (49). A systematic review and meta-analysis by Spencer and colleagues reports higher odds of all-cause disabling chronic conditions for children from low SES (49). Children with complex chronic conditions from a low socioeconomic background might thus be a particularly vulnerable group, concerning both their chronic condition and their mental health. Following priorities set out by the UN 'Research Roadmap for the COVID-19 Recovery', future research should investigate into potential new forms of vulnerability as a result of the pandemic, taking the complex interaction of multiple coexisting factors into account with the aim to identify measures to address the systemic causes of socioeconomic inequities in health (50).

\section{Disease Complexity and Mental Health}

Children with complex chronic disease had three times the odds of parent-reported mental health problems compared to healthy children in the baseline model. In the stratified analysis by disease complexity, the odds of mental health problems by both a positive screening for depression in the WHO-5 and family conflict increased with the degree of disease complexity. Children with complex chronic disease whose parents screened positive for depression or reported an increase in family conflict had more than two times the odds of parent-reported mental health problems compared to the baseline group.

In our sample, children with a variety of conditions were included, among them behavioural problems, physical and cognitive impairment as well as children with home-ventilation. It is likely that for some of the children with high disease complexity behavioural or emotional problems are part of their condition.

However, the interplay of child and parental mental health warrants further consideration. Parents of children with chronic conditions face a higher risk of psychological distress and depression $(27,48)$. Several studies have explored the additional mental health burden of carers of children with chronic conditions and disabilities during the COVID19 pandemic. Willner et al. report moderate to severe levels of depression in $45 \%$ of carers of children with intellectual disability (51). Bentenuto et al. investigated factors determining the psychological impact of lockdown measures on parents of children with neurodevelopmental disorders. They report both an increase in parental stress as well as an increase in child behavioural problems (27). Grumi et al. describe the effect of discontinued rehabilitation services for children with neurodevelopmental disorders on the mental health response of caregivers. They found elevated parental scores for stress, anxiety and depression as a consequence of managing the specific special needs of their children without external support (28). The high odds of mental health problems in children with complex chronic disease in our study sample might thus, as a parentreported outcome measure, equally reflect on parental mental health considering the reciprocity of the relationship.

\section{LIMITATIONS}

Despite the large number of participants, the results and in particular the generalisability are limited by the nonrepresentative nature of our sample. In addition, due to the snowballing process of recruitment we do not know exactly through which channels the comparison group of healthy children was reached. Moreover, a majority of respondents had a high education level, whereas lower education and occupational levels are underrepresented leading to responding bias. Furthermore, the cross-sectional design does not allow inference of causality with regards to the main outcome measures. As mentioned above, the presence of parental mental health problems may be reflected in child mental health problems, but child mental health problems may also affect parental mental health.

Regarding statistical analyses, the percentage of missing values ranged from $15-24 \%$ for all variables. Instead of restricting the analysis to complete responses with a risk of selection bias and loss of precision, we decided to perform multiple 
linear imputation for outcome and exposure variables prior to conducting hierarchical logistic regression modelling. However, multiple imputation cannot neutralise measurement errors completely and thus is a compromise in dealing with missing data. Though following an established methodology (33), the construction of the SES-index as a composite measure of socioeconomic status might be a source of bias. The household net income, from which the net equivalent income was calculated as one dimension of the SES-index, was only available as a categorical and not as a continuous variable. The weighting by household size was thus performed on the respective income categories and the actual net equivalent income was then inferred from the income ranges assigned to the original categories. Therefore the potential for under- or overestimating the actual household net equivalent income is high, which also impacts the validity of the SES index.

\section{CONCLUSION}

This study highlights inequalities in parent-reported child mental health outcomes by socioeconomic status and disease complexity in a large sample of German families with and without children with special health care needs. It shows a high burden of both child and parental mental health problems in the whole study population and identifies children from low SES with complex chronic disease as a particularly vulnerable group concerning the effect of pandemic measures on their mental health outcomes. COVID-19 has already been described as a syndemic, a term which acknowledges the complex interaction of pre-existing conditions, social and biological factors and calls for an integrated approach in response to the pandemic $(52,53)$. Long-term policies, which put children at the centre, aim at reducing health inequalities, and mitigate the unequal impact of the pandemic, should be an integral part of the COVID19 response.

\section{DATA AVAILABILITY STATEMENT}

The raw data supporting the conclusions of this article will be made available by the authors, without undue reservation.

\section{REFERENCES}

1. Marmot M, Allen J. COVID-19: Exposing and amplifying inequalities. J Epidemiol Community Health. (2020) 74:6812. doi: 10.1136/jech-2020-214720

2. Whitehead M, Barr B, Taylor-Robinson D. Covid-19: We are not "All in it Together"-Less Privileged in Society are Suffering the Brunt of the Damage. BMJ Opinion. (2020). Available from: https://blogs.bmj.com/ bmj/2020/05/22/covid-19-we-are-not-all-in-it-together-less-privilegedin-society-are-suffering-the-brunt-of-the-damage/ (accessed June 1, 2021).

3. Wright L, Steptoe A, Fancourt D. Are we all in this together? Longitudinal assessment of cumulative adversities by socioeconomic position in the first 3 weeks of lockdown in the UK. J Epidemiol Commun Health. (2020) 74:6838. doi: 10.1136/jech-2020-214475

\section{ETHICS STATEMENT}

This study was reviewed and approved by the Ethics Committee of Freiburg University (Approval number 377/20). The participants provided their written informed consent to participate in this study.

\section{AUTHOR CONTRIBUTIONS}

$\mathrm{MB}, \mathrm{TL}$, and $\mathrm{AH}$ conceptualised the study. AG, MB, and TL developed the methodology. TL, AM, and $\mathrm{HH}$ recruited participants. AG and $\mathrm{MB}$ conducted data analysis. AG, MB, and SI were responsible for data curation. AG wrote the original draft. $\mathrm{AG}, \mathrm{MB}$, and $\mathrm{TL}$ edited and reviewed the manuscript. $\mathrm{MB}$ and TL provided project supervision. TL was in charge of project administration and funding acquisition. All authors contributed to the article and approved the submitted version.

\section{FUNDING}

This research was funded by the Volkswagen Foundation, grant number Az 990622. The article processing charge was funded by the Baden-Wuerttemberg Ministry of Science, Research and Art and the University of Freiburg in the funding programme Open Access Publishing.

\section{ACKNOWLEDGMENTS}

The authors would like to thank AM, HH and Kathrin JackelNeusser from the steering committee of the Kindernetzwerk e.V. for their support in the recruitment process and their valuable contributions to the survey development.

\section{SUPPLEMENTARY MATERIAL}

The Supplementary Material for this article can be found online at: https://www.frontiersin.org/articles/10.3389/fped. 2022.759066/full\#supplementary-material
4. The Lancet Child \& Adolescent Health. Prioritising children's rights in the COVID-19 response. Lancet Child Adolesc Health. (2020) 4:479. doi: 10.1016/S2352-4642(20)30172-3

5. Rajmil L, Hjern A, Boran P, Gunnlaugsson G, Kraus de. Camargo O, Raman S. Impact of lockdown and school closure on children's health and well-being during the first wave of COVID-19: a narrative review. BMJ Paediatr Open. (2021) 5:e001043. doi: 10.1136/bmjpo-2021-001043

6. Crawley E, Loades M, Feder G, Logan S, Redwood S, Macleod J. Wider collateral damage to children in the UK because of the social distancing measures designed to reduce the impact of COVID-19 in adults. BMJ Paediatr Open. (2020) 4:1-4. doi: 10.1136/bmjpo-2020-000701

7. United Nations Sustainable Development Group. Policy Brief: The Impact of on children. New York. (2020). Available online at: https://unsdg.un. org/resources/policy-brief-impact-covid-19-children (accessed January 25, 2022). 
8. Patrick SW, Henkhaus LE, Zickafoose JS, Lovell K, Halvorson A, Loch S, et al. Well-being of Parents and Children During the COVID-19 Pandemic: a National Survey. Pediatrics. (2020) 146:e2020016824. doi: 10.1542/peds.2020-016824

9. Hefferon C, Taylor C, Bennett D, Falconer C, Campbell M, Williams JG, et al. Priorities for the child public health response to the COVID-19 pandemic recovery in England. Arch Dis Child. (2021) 106:533-8. doi: 10.1136/archdischild-2020-320214

10. Kyeremateng $\mathrm{R}$, Oguda L, Asemota O. COVID-19 pandemic: Health inequities in children and youth. Arch Dis Child. (2021) 0:4-6. doi: 10.1136/archdischild-2020-320170

11. United Nations Sustainable Development Group. Policy Brief : COVID-19 and the Need for Action on Mental Health. New York. (2020). Available online at: https://unsdg.un.org/resources/policy-brief-covid-19-and-needaction-mental-health

12. Gadermann AC, Thomson KC, Richardson CG, Gagné M, Mcauliffe C, Hirani $\mathrm{S}$, et al. Examining the impacts of the COVID-19 pandemic on family mental health in Canada: findings from a national cross-sectional study. BMJ Open. (2021) 11:1-11. doi: 10.1136/bmjopen-2020-042871

13. Krass P, Dalton E, Doupnik SK, Esposito J. US pediatric emergency department visits for mental health conditions during the COVID-19 pandemic. JAMA Netw Open. (2021) 4:8-11. doi: 10.1001/jamanetworkopen.2021.8533

14. Vizard T, Sadler K, Ford T, Newlove-Delgado T, McManus S, Marcheselli F, et al. Mental Health of Children and Young People in England, 2020. NHS Digital. (2020). Available online at: https://files.digital.nhs.uk/CB/C41981/ mhcyp_2020_rep.pdf (accessed January 25, 2022)

15. Newlove-Delgado T, McManus S, Sadler K, Thandi S, Vizard T, Cartwright C, et al. Child mental health in England before and during the COVID-19 lockdown. Lancet Psychiatry. (2021) 8:353-4. doi: 10.1016/S2215-0366(20)30570-8

16. Tromans S, Chester V, Harrison H, Pankhania P, Booth H, Chakraborty N. Patterns of use of secondary mental health services before and during COVID-19 lockdown: observational study. BJPsych Open. (2020) 6:e117. doi: 10.1192/bjo.2020.104

17. Ravens-Sieberer U, Kaman A, Erhart M, Devine J, Schlack R, Otto C. Impact of the COVID-19 pandemic on quality of life and mental health in children and adolescents in Germany. Eur Child Adolesc Psychiatry. (2021) 25:111. doi: 10.1007/s00787-021-01726-5

18. Van Lancker W, Parolin Z. COVID-19, school closures, and child poverty: a social crisis in the making. Lancet Public Health. (2020) 5:e243e244. doi: 10.1016/S2468-2667(20)30084-0

19. Armitage R, Nellums LB. Considering inequalities in the school closure response to COVID-19. Lancet Glob Health. (2020) 8:e644. doi: 10.1016/S2214-109X(20)30116-9

20. Gassman-Pines A, Ananat EO, Fitz-Henley J. COVID-19 and Parent-Child Psychological Well-being. Pediatrics. (2020) 146:e2020007294. doi: 10.1542/peds.2020-007294

21. Ezpeleta L, Navarro JB. de la Osa N, Trepat E, Penelo E. Life conditions during COVID-19 lockdown and mental health in Spanish adolescents. Int J Environ Res Public Health. (2020) 17:1-13. doi: 10.3390/ijerph17197327

22. Reiss F, Meyrose AK, Otto C, Lampert T, Klasen F, Ravens-Sieberer U. Socioeconomic status, stressful life situations and mental health problems in children and adolescents: Results of the German BELLA cohort-study. PLoS ONE. (2019) 14:1-16. doi: 10.1371/journal.pone.0213700

23. Ravens-Sieberer U, Kaman A, Otto C, Adedeji A, Napp AK, Becker $\mathrm{M}$, et al. Seelische Gesundheit und psychische Belastungen von Kindern und Jugendlichen in der ersten Welle der COVID-19-Pandemie Ergebnisse der COPSY-Studie. Bundesgesundheitsblatt - Gesundheitsforsch Gesundheitsschutz. (2021) 64:1512-21. doi: 10.1007/s00103-021-03291-3

24. Lampert T, Hoebel J, Kuntz B, Finger JD, Hölling H, Lange M, et al. Gesundheitliche Ungleichheiten bei Kindern und Jugendlichen in Deutschland - Zeitliche Entwicklung und Trends der KiGGS-Studie. J Heal Monit. (2019) 4:16-40. doi: 10.25646/5867

25. Li W, Wang Z, Wang G, Ip P, Sun X, Jiang Y, et al. Socioeconomic inequality in child mental health during the COVID-19 pandemic: First evidence from China. J Affect Disord. (2021) 287:8-14. doi: 10.1016/ j.jad.2021.03.009
26. Houtrow A, Harris D, Molinero A, Levin-Decanini T, Robichaud C. Children with disabilities in the United States and the COVID-19 pandemic. J Pediatr Rehabil Med. (2020) 13:415-24. doi: 10.3233/PRM-200769

27. Bentenuto A, Mazzoni N, Giannotti M, Venuti P, de Falco S. Psychological impact of Covid-19 pandemic in Italian families of children with neurodevelopmental disorders. Res Dev Disabil. (2021) 109:1-11. doi: 10.1016/j.ridd.2020.103840

28. Grumi S, Provenzi L, Gardani A, Aramini V, Dargenio E, Naboni C, et al. Rehabilitation services lockdown during the COVID-19 emergency: the mental health response of caregivers of children with neurodevelopmental disabilities. Disabil Rehabil. (2020) 43:27-32. doi: 10.1080/09638288.2020.1842520

29. Cacioppo M, Bouvier S, Bailly R, Houx L, Lempereur M, Mensah-Gourmel J, et al. Emerging health challenges for children with physical disabilities and their parents during the COVID-19 pandemic: The ECHO French survey. Ann Phys Rehabil Med. (2021) 64:101429. doi: 10.1016/j.rehab.2020.08.001

30. Kuper H, Banks LM, Bright T, Davey C, Shakespeare T. Disability-inclusive COVID-19 response: What it is, why it is important and what we can learn from the United Kingdom's response. Wellcome Open Res. (2020) 5:1-8. doi: 10.12688/wellcomeopenres.15833.1

31. Asbury K, Fox L, Deniz E, Code A, Toseeb U. How is COVID-19 Affecting the Mental Health of Children with Special Educational Needs and Disabilities and Their Families? J Autism Dev Disord. (2021) 51:177280. doi: 10.1007/s10803-020-04577-2

32. Castro-Kemp S, Mahmud A. School Closures and Returning to School: views of parents of children with disabilities in England during the Covid-19 pandemic. Front Educ. (2021) 6. doi: 10.3389/feduc.2021.666574

33. Lampert T, Hoebel J, Kuntz B, Müters S, Kroll LE. Messung des sozioökonomischen Status und des subjektiven sozialen Status in KiGGS Welle 2. J Heal Monit. (2018) 3:114-33. doi: 10.17886/RKI-GBE-2018-016

34. Goodman R. The strengths and difficulties questionnaire: a research note. J Child Psychol Psychiatry Allied Discip. (1997) 38:581-6. doi: 10.1037/t00540-000

35. Woerner W, Becker A, Friedrich C, Klasen H, Goodman R, Rothenberger A. Normierung und evaluation der deutschen elternversion des Strengths and Difficulties Questionnaire (SDQ): ergebnisse einer repräsentativen felderhebung. Z Kinder Jugendpsychiatr Psychother. (2002) 30:105-12. doi: 10.1024//1422-4917.30.2.105

36. Woerner W, Becker A, Rothenberger A. Normative data and scale properties of the German parent SDQ. Eur Child Adolesc Psychiatry. (2004) 13 Suppl 2:II3-10. doi: 10.1007/s00787-004-2002-6

37. Rothenberger A, Becker A, Erhart M, Wille N, Ravens-Sieberer U. Psychometric properties of the parent strengths and difficulties questionnaire in the general population of German children and adolescents: Results of the BELLA study. Eur Child Adolesc Psychiatry. (2008) 17(Suppl. 1):99105. doi: 10.1007/s00787-008-1011-2

38. Croft S, Stride C, Maughan B, Rowe R. Validity of the strengths and difficulties questionnaire in preschool-aged children. Pediatrics. (2015) 135:e1210-e1219. doi: 10.1542/peds.2014-2920

39. Klein AM, Otto $\mathrm{Y}$, Fuchs $\mathrm{S}$, Zenger $\mathrm{M}$, Von Klitzing $\mathrm{K}$ Psychometric properties of the parent-rated SDQ in preschoolers. Eur J Psychol Assess. (2013) 29:96-104. doi: 10.1027/1015-5759/ a000129

40. Robert Koch Institut. KiGGS Welle 2- Gesundheitliche Lage von Kindern und Jugendlichen. J Heal Monit. (2018) 3:1-120.

41. Winther Topp C, Østergaard SD, Søndergaard S, Bech P. The WHO-5 wellbeing index: a systematic review of the literature. Psychother Psychosom. (2015) 84:167-76. doi: 10.1159/000376585

42. Bethell CD, Read D, Stein REK, Blumberg SJ, Wells N, Newacheck PW. Identifying children with special health care needs: development and evaluation of a short screening instrument. Ambul Pediatr. (2002) 2:3848. doi: 10.1037/t32135-000

43. Bethell CD, Blumberg SJ, Stein REK, Strickland B, Robertson J, Newacheck PW. Taking stock of the CSHCN screener: a review of common questions and current reflections. Acad Pediatr. (2015) 15:165-76. doi: 10.1016/j.acap.2014.10.003

44. Matiz LA, Robbins-Milne L, Rausch JA. EMR adaptations to support the identification and risk stratification of children with special health 
care needs in the medical home. Matern Child Health J. (2019) 23:91924. doi: 10.1007/s10995-018-02718-9

45. Mauz E, Schmitz R, Poethko-Müller C. Kinder und Jugendliche mit besonderem Versorgungsbedarf im Follow-up: Ergebnisse der KiGGS-Studie Kinder und Jugendliche mit besonderem Versorgungsbedarf im Followup: Ergebnisse der KiGGS-Studie 2003-2012. J Heal Monit. (2017) 2:45-65. doi: 10.17886/RKI-GBE-2017-051

46. Hapke U, Cohrdes C, Nübel Robert J. Depressive Symptomatik im europäischen Vergleich - Ergebnisse des European Health Interview Survey (EHIS) 2. J Heal Monit. (2019) 4:62-70. doi: 10.25646/6221

47. Fegert JM, Vitiello B, Plener PL, Clemens V. Challenges and burden of the Coronavirus 2019 (COVID-19) pandemic for child and adolescent mental health: a narrative review to highlight clinical and research needs in the acute phase and the long return to normality. Child Adolesc Psychiatry Ment Health. (2020) 14:20. doi: 10.1186/s13034-020-00329-3

48. Mazza C, Ricci E, Marchetti D, Fontanesi L, Giandomenico S Di, Verrocchio MC, et al. How personality relates to distress in parents during the COVID-19 lockdown: The mediating role of child's emotional and behavioral difficulties and the moderating effect of living with other people. Int J Environ Res Public Health. (2020) 17:6236. doi: 10.3390/ ijerph17176236

49. Spencer NJ, Blackburn CM, Read JM. Disabling chronic conditions in childhood and socioeconomic disadvantage: a systematic review and meta-analyses of observational studies. BMJ Open. (2015) 5:e007062. doi: 10.1136/bmjopen-2014-007062

50. United Nations. UN Research Roadmap for the COVID-19 Recovery. New York. (2020). Available online at: https://www.un.org/en/coronavirus/ communication-resources/un-research-roadmap-covid-19-recovery (accessed January 25, 2022).
51. Willner P, Rose J, Stenfert Kroese B, Murphy GH, Langdon PE, Clifford C, et al. Effect of the COVID-19 pandemic on the mental health of carers of people with intellectual disabilities. J Appl Res Intellect Disabil. (2020) 33:1523-33. doi: $10.1111 /$ jar.12811

52. Horton R. Offline: COVID-19 is not a pandemic. Lancet. (2020) 396:874. doi: 10.1016/S0140-6736(20)32000-6

53. Bambra C, Riordan R, Ford J, Matthews F. The COVID-19 pandemic and health inequalities. J Epidemiol Commun Health. (2020) 74:9648. doi: $10.1136 /$ jech-2020-214401

Conflict of Interest: The authors declare that the research was conducted in the absence of any commercial or financial relationships that could be construed as a potential conflict of interest.

Publisher's Note: All claims expressed in this article are solely those of the authors and do not necessarily represent those of their affiliated organizations, or those of the publisher, the editors and the reviewers. Any product that may be evaluated in this article, or claim that may be made by its manufacturer, is not guaranteed or endorsed by the publisher.

Copyright (c) 2022 Geweniger, Barth, Haddad, Högl, Insan, Mund and Langer. This is an open-access article distributed under the terms of the Creative Commons Attribution License (CC BY). The use, distribution or reproduction in other forums is permitted, provided the original author(s) and the copyright owner(s) are credited and that the original publication in this journal is cited, in accordance with accepted academic practice. No use, distribution or reproduction is permitted which does not comply with these terms. 